[Article]

\title{
用于单分子动力学实验的微流控混合器
}

\author{
支泽勇 ${ }^{1,3}$ 刘鹏程 ${ }^{1,3}$ 黄岩谊 ${ }^{2,3}$ 赵新生 ${ }^{1,3,{ }^{*}}$ \\ ('北京大学化学与分子工程学院化学生物学系, 北京分子科学国家实验室, 分子动态与稳态结构国家重点实验室, \\ 北京 $100871 ;{ }^{2}$ 北京大学工学院, 北京 100871; ${ }^{3}$ 北京大学生物动态光学成像中心, 北京 100871)
}

摘要: 设计制作了用于单分子动力学实验的微流控混合器, 该混合器用聚二甲基硅氧烷(PDMS)芯片和石英 载玻片密封而成, 具有低的荧光背景, 广泛的生物相容性, 结合激光共聚焦显微镜能够在非平衡态下进行单分 子苂光探测. 我们设计的压力控制系统和进样流路方便而稳定, 保证了微流路中流形的长时间稳定, 从而实现 了样品流速和流量的精准控制. 这些技术特点保证了单分子探测得到准确和高信噪比的结果. 利用蛋白质的塌 缩过程远快于混合过程的特点, 采用荧光标记的金黄色葡萄球菌核酸酶作为指示物, 分辨出蛋白质变性态的特 征峰, 并利用变性态的荧光共振能量传递效率随时间的变化表征出混合器在适合于单分子探测条件下的混合 时间为 $150 \mathrm{~ms}$.

关键词：微流控混合；单分子探测；荧光共振能量传递；蛋白质折叠；金黄色葡萄球菌核酸酶 中图分类号: 0643

\section{A Microfluidic Mixer for Single-Molecule Kinetics Experiments}

\author{
ZHI Ze-Yong ${ }^{1,3} \quad$ LIU Peng-Cheng ${ }^{1,3}$ HUANG Yan-Yi ${ }^{2,3} \quad$ ZHAO Xin-Sheng ${ }^{1,3, *}$ \\ ('Beijing National Laboratory for Molecular Sciences, State Key Laboratory for Structural Chemistry of Unstable and Stable \\ Species, Department of Chemical Biology, College of Chemistry and Molecular Engineering, Peking University, Beijing 100871, \\ P. R. China; ${ }^{2}$ College of Engineering, Peking University, Beijing 100871, P. R. China; ${ }^{3}$ Biodynamic Optical Imaging Center, \\ Peking University, Beijing 100871, P. R. China)
}

\begin{abstract}
We designed and built a microfluidic mixer based on the principle of hydrodynamic focusing governed by Navier-Stokes equation for single-molecule kinetics experiments. The mixer is a cast of poly(dimethylsiloxane) (PDMS) sealed with transparent fused-silica coverglass, which results in low fluorescence background and broad biological compatibility and this enables single-molecule fluorescence detection under nonequilibrium conditions. The pressure regulated sample delivery system is convenient for loading a sample and allows for precise and stable flow velocity control. The combination of microfluidic mixer and single-molecule fluorescence resonance energy transfer (smFRET) allows us to measure the time course of the distribution of the smFRET efficiency in protein folding. We used the fact that denatured protein collapses much faster than the mixing process to characterize the mixing time using donor and acceptor dyes labeled staphylococcal nuclease (SNase) as an smFRET efficiency indicator. By monitoring the smFRET efficiency of denatured SNase during the course of mixing, we determined that the mixing time was $150 \mathrm{~ms}$ under conditions suitable for single-molecule detection.
\end{abstract}

Key Words: Microfluidic mixing; Single-molecule detection; Fluorescence resonance energy transfer; Protein folding; Staphylococcal nuclease

Received: April 27, 2011; Revised: June 1, 2011; Published on Web: June 9, 2011.

"Corresponding author. Email: zhaoxs@pku.edu.cn; Tel: +86-10-62751727.

The project was supported by the National Natural Science Foundation of China (20733001, 20973015) and National Key Basic Research Program of China (973) (2006CB910300, 2010CB912302).

国家自然科学基金(20733001, 20973015)和国家重点基础研究发展规划项目(973) (2006CB910300, 2010CB912302)资助

(C) Editorial office of Acta Physico-Chimica Sinica 


\section{Introduction}

The protein folding study involves structure, thermodynamics, and kinetics. The kinetics of protein folding concerns the folding pathway, the rate, and the energy landscape..$^{1-3}$ In order to characterize the protein folding, experiments needs to be performed both under equilibrium and nonequilibrium conditions. ${ }^{4,5}$ Single-molecule fluorescence resonance energy transfer (smFRET) can separate the subpopulations of the protein molecules beyond the capacity of common ensemble experiments. ${ }^{6-8}$ Equilibrium smFRET experiments have addressed a number of important issues in protein folding by resolving the thermodynamic states and the sizes of the protein molecules within a heterogeneous mixture. ${ }^{9-12}$

Microfluidic laminar-flow mixers have been applied in many fields for kinetics measurements of biomolecular conformational changes with ultrafast mixing times. ${ }^{13-18}$ Microfabricated mixers often utilize hydrodynamic focusing to squeeze the sample stream into submicron width to achieve extremely fast mixing through molecular diffusion. ${ }^{19}$ Compared with traditional stopped flow method, the microfluidic mixer has advantages of submillisecond mixing time, greater uniformity, and low sample consumption. The mixing devices have the capacity of single-molecule fluorescence detection with the accessible window for high numerical aperture objectives. ${ }^{20-22}$ Ensemble nonequilibrium experiments can only measure the kinetics of protein folding with the averaged and overall information, while the individual processes were indirectly resolved with kinetic modeling. ${ }^{23}$ Single-molecule fluorescence detection under nonequilibrium conditions can be used to study the protein folding kinetics with the full distribution of conformations to separate the unfolded and folded states. ${ }^{24}$ The combination of smFRET and a microfluidic mixer will generate novel insights into protein folding mechanism and is a powerful method to study biomolecular interactions and reactions.

Here, we constructed a microfluidic mixing system suitable for single-molecule fluorescence detection, which requires high signal-to-noise ratio, low protein adhesion, and stable flow rate for a long time. The mixing device was made of a cast of poly(dimethylsiloxane) (PDMS) sealed by a microscopic coverglass. The mixer channel pattern was designed to achieve comprehensive mixing at a minimal dead time and the flow was then slowed down to provide sufficient dwell time for single-molecule detection, and the device possessed wide biological compatibility. The mixer was easy to fabricate with common apparatus and could be improved for faster mixing with finer design and fabrication. The device was optimized to reduce the protein adhesion to the channel walls by using a long period of cure time and by adding wild-type protein at micromolar concentration into the injected sample. Novel design was implemented on the pressure regulation and sample-inlet lines so as to achieve a stable hydrodynamic flow in the mixer for many hours, which was a key factor for the single-molecule fluorescence measurements. To our knowledge, for the first time the mixing process along the mixing channel using smFRET histograms and the accurate flow velocity profile using fluorescence correlation spectroscopy (FCS) were characterized simultaneously. Then, the mixing time was determined by monitoring the collapse of denatured staphylococcal nuclease (SNase). ${ }^{25}$ Although the mixing system was designed for single-molecule experiments, the mixer can also be used in ensemble measurements with a submillisecond time resolution by applying higher pressures.

\section{Materials and methods}

\subsection{Construction of microfluidic mixing device}

The channel drawing was created using computer-aided software. The patten was written by an electron beam on a chrome coated glass plate to generate the mask. The microfluidic mixer was made of a PDMS chip (RTV 615, GE Silicones) sealed to a No.1 coverglass (Fisher Scientific). The master was fabricated by contact photolithography. A $20 \mu \mathrm{m}$ layer of SU-8 2010 (MicroChem, U.S.) was spin-coated onto a cleaned silicon wafer, after a soft bake the photoresist was exposed to UV light with $144 \mathrm{~mJ} \cdot \mathrm{cm}^{-2}$ through the mask and the wafer was then baked on a hot-plate for $4.5 \mathrm{~min}$ at $95{ }^{\circ} \mathrm{C}$ and developed.

In order to prevent PDMS adhesion, the master was silanized by exposure to a vapor of chlorotrimethylsilane (TMCS) in a sealed box for $15 \mathrm{~min}$. To make the PDMS chip, a $\sim 4 \mathrm{~mm}$ thick layer of PDMS mixture, five parts by weight of PDMS and one part of crosslinking agent, was poured onto the mold and cured at $80^{\circ} \mathrm{C}$ for $10 \mathrm{~min}$. The PDMS chip was then peeled off from the master, trimmed to the individual chip size and cured at $80^{\circ} \mathrm{C}$ for another $8 \mathrm{~h}$. Finally, the PDMS chips were punched to generate inlet and outlet ports and bonded to a coverglass permanently using an air plasma.

\subsection{Sample delivery system}

A pressure-driven pump was used because it is applicable in the situation of low flow rate. ${ }^{26}$ The pressure-driven sample delivery creates stable flow rate about $0.1 \mathrm{~nL} \cdot \mathrm{s}^{-1}$ in the centre inlet for many hours. The protein sample and buffer were delivered into the inlets from two reservoirs which were made of $0.6 \mathrm{~mL}$ centrifuge tubes and PDMS plugs with two punched holes for Gauge 18 needles. The two sample reservoirs were connected to compressed air, and the pressures were regulated by two accurate pressure regulators (8286, Porter Instruments, U.S.) and measured with two accurate digital pressure gauges (DPG4000, Omega, U.S.) respectively. Another high pressure regulator having a range of $0-250 \mathrm{kPa}$ was built to drive the solutions into the mixer in a faster flow speed, which can also be used in rapid mixing ensemble experiments.

In order to maintain the flow speed around $1 \mathrm{~mm} \cdot \mathrm{s}^{-1}$ in the measurement channel for single-molecule detection, the side inlet pressure was regulated typically to $6.00 \mathrm{kPa}$ and the centre inlet pressure was $7.80 \mathrm{kPa}$. The resolution of the regulators was about $0.01 \mathrm{kPa}$ with a careful tuning. The pressures would change a little for individual mixers due to small deviation in 
the fabrication. The high pressure regulator was used to drive the solutions into the mixer at $150 \mathrm{kPa}$ to focus the sample stream in a short time. If the solutions were pumped into the mixer by the precise but low pressure regulators, hours would be needed to obtain a stable focused sample stream. After the formation of the focused stream, the pressures of the reservoirs were switched to the precise and low pressure regulators for single-molecule experiments.

\subsection{Single-molecule confocal microscope}

Single-molecule fluorescence measurements were performed on a home-built dual-channel confocal fluorescence mi$\operatorname{croscope}^{27,28}$ based on a TE2000 microscope (Nikon). The labeled protein sample was excited by a solid-state laser (MLLIII-532, CNI) at $532 \mathrm{~nm}$ with $100 \mu \mathrm{W}$ for experiments on the coverglass and $130 \mu \mathrm{W}$ in the mixer, focused through an oil immersion objective $(100 \times$, NA 1.3, Nikon, Japan). The donor and acceptor fluorescences, seperated from the excitation light by a dichroic mirror (Z532, Chroma, U.S.), were collected by the same objective and spatially filtered using a $30 \mu \mathrm{m}$ pinhole. The passed fluorescence was separated into donor and acceptor components with a second dichroic mirror (FF650-Di01, Semrock, U.S.) and two final filters (FF01-593/40 and FF01-692/ 40 , Semrock, U.S.) for the donor and acceptor channels, respectively. Each component was detected by a photon-counting Avalanche Photodiode (SPCM-AQRH-14, PerkinElmer Optoelectronics, U.S.). Fluorescence intensities were recorded with a photon counters card (PMS-400A, Becker \& Hickl, Germany). Autocorrelation functions were simultaneously recorded using a multiple-digital hardware correlator device (Flex02-01D, www.correlator. com, U.S.).

The raw single-molecule fluorescence data were corrected for several factors ${ }^{11,29}$ to obtain the actual FRET efficiency, including background, differences in quantum yields, different collection efficiencies of the donor and acceptor channels, cross-talk, and direct excitation of the acceptor.

\subsection{Protein expression, purification and labeling}

Expression, purification, and labeling of the mutant of SNase, K28C-H124C, were carried out as described previously. ${ }^{30}$ Briefly, The mutant proteins were reduced with excess of Dithiothreitol (DTT, Sigma, U.S.) followed by chromatography in labeling buffer to remove the excess DTT. Site-specific labeling was achieved by reaction with thiol-reactive fluorescence dyes Alexa Fluor 555 and Alexa Fluor 647 (Invitrogen, U.S.). Free dyes were removed through a PD-10 Desalting Column (GE Healthcare, U.S.) and the labeled protein solution was stored at $-80{ }^{\circ} \mathrm{C}$ with $10 \%$ glycerol.

Labeled SNase of 50-100 pmol $\cdot \mathrm{L}^{-1}$ was diluted in $1 \mu \mathrm{mol} \cdot$ $\mathrm{L}^{-1}$ unlabeled SNase in Tris- $\mathrm{HCl}$ buffer $\left(\mathrm{pH} 7.8,50 \mathrm{mmol} \cdot \mathrm{L}^{-1}\right.$ Tris- $\mathrm{HCl}$ with $100 \mathrm{mmol} \cdot \mathrm{L}^{-1} \mathrm{NaCl}$ ) at appropriate $\mathrm{GdmCl}$ concentration. The dwell time bin was $1 \mathrm{~ms}^{10}$ and a threshold was set at 50 counts in the sum of photon counts from the two channels.

\section{Results and discussion}

\subsection{Controbility of the mixer}

The microfluidic mixer shown in Fig.1 was designed with a resistance model using Ohm's law. ${ }^{19}$ The relationship of flow rate, pressure difference, and flow impedance in a rectangular pipe can be described with the following equation: ${ }^{31}$

$$
Q=\left(-\frac{\mathrm{d} p}{\mathrm{~d} l}\right) \cdot \frac{h w^{3}}{12 \eta} \cdot\left[1-\frac{192 w}{\pi^{5} h} \cdot \sum_{k=1,3,5 \cdots}^{\infty} \frac{\tanh \left(\frac{k \pi h}{2 w}\right)}{k^{5}}\right]
$$

where $Q$ is the flow rate, $\mathrm{d} p / \mathrm{d} l$ is the pressure gradient, $w$ is the channel width, $h$ is the channel height, and $\eta$ is the solution viscosity. The two side channels of an actual microfluidic mixer were connected to the same entry, reducing a set of pressure regulator system. The channel dimensions and the flow impedances are shown in Table 1. The impedance of the mixing neck is less than $1 \%$ of the other channels which can be ignored in the calculation. When the change of inlets pressure is $0.05 \mathrm{kPa}$, the maximum pressure fluctuation of the system, the change in

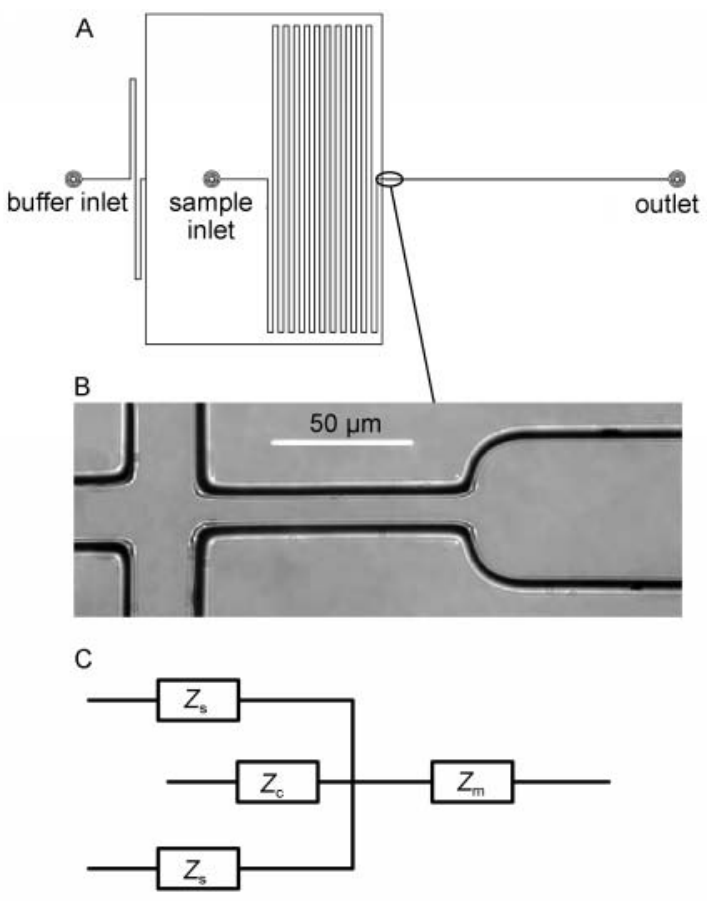

Fig.1 (A) Scheme of the microfluidic mixer, (B) a white light microscopy image of the microfluidic mixing region, (C) the impedance model for the designed mixer

The height of the channels in figure B is $20 \mu \mathrm{m}$. In figure C: $Z_{\mathrm{c}}$ and $Z_{\mathrm{m}}$ are the impedances of the centre and measurement channels, respectively; $Z_{\mathrm{s}}$ is the impedance equivalent to the side flow impedance of a mixer with two parallel side channels.

Table 1 Channel dimensions and impedances

\begin{tabular}{|c|c|c|c|c|}
\hline \multirow{2}{*}{ Channel } & Depth & Width & Length & Impedance \\
\hline & $\mu \mathrm{m}$ & $\mu \mathrm{m}$ & $\mathrm{mm}$ & $\left(\mathrm{kPa} \cdot \mathrm{s} \cdot \mathrm{nL}^{-1}\right)$ \\
\hline side channel ${ }^{a}$ & 20 & 20 & 62 & 11.1 \\
\hline centre channel & 20 & 20 & 278 & 50.0 \\
\hline measurement channel & 20 & 50 & 12 & 0.48 \\
\hline
\end{tabular}

${ }^{a}$ The channel length is the equivalence to a mixer of the side channel with two parallel lines. 

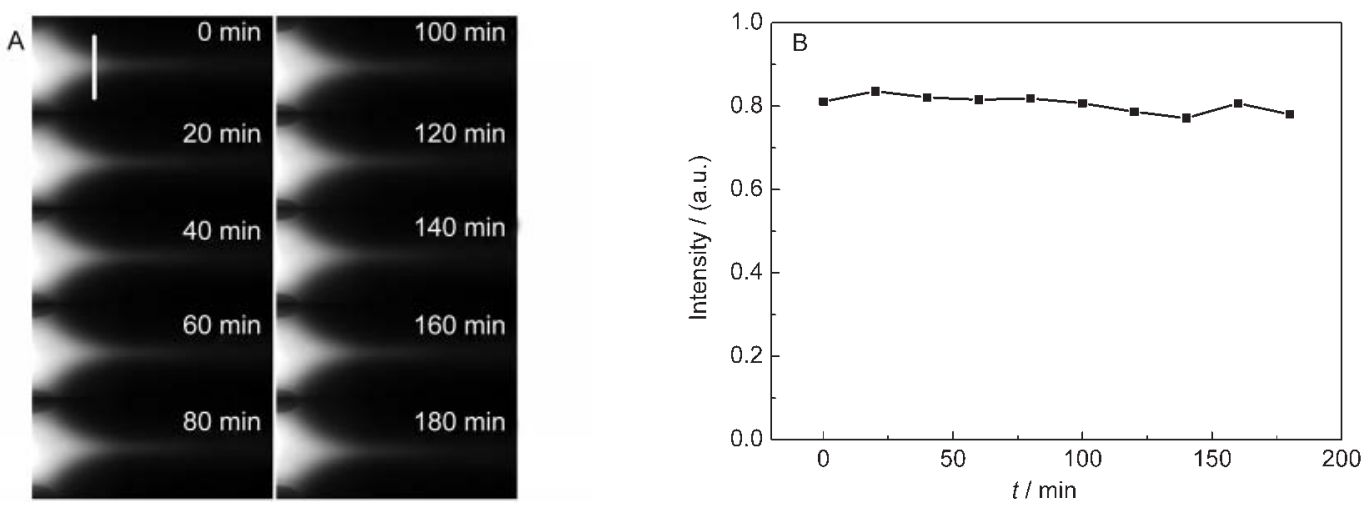

Fig.2 Flow stability in the microfluidic mixer

(A) fluorescence images of focused dye solution stream over hours; The intensity profiles of the cross line (the white line) for all images are extracted. (B) The peak intensities of the cross lines are plotted as time, which is $11270 \pm 280$, indicating that the flow rate fluctuation was about $2 \%$.

flow ratio is about $2 \%$, so that the mixer can maintain a stable flow rate for smFRET measurement.

The robustness of the flow velocity was examined by fluorescence images over several hours. The pressure was set to maintain appropriate hydrodynamic focusing and a flow rate in the detection channel around $1 \mu \mathrm{mm} \cdot \mathrm{s}^{-1}$. A $0.1 \mu \mathrm{mol} \cdot \mathrm{L}^{-1}$ AF532 solution with $0.01 \%$ Tween 20 (Pierce) to prevent dye adhesion was delivered into the centre inlet and water was injected into the side inlets. The focused dye solution stream was excited by mercury lamp and recorded by a CCD camera through an emission filter (Fig.2). The high stability of the flow rate guaranteed the fidelity of single-molecule measurements over a long time for a good signal-to-noise ratio. When a denatrued potein sample with $2 \mathrm{~mol} \cdot \mathrm{L}^{-1} \mathrm{GdmCl}$ was fed into the centre inlet, simulation reslults showed that the concentration deviation of the denatrurant was less than $0.05 \mathrm{~mol} \cdot \mathrm{L}^{-1}$. As a consequence, the protein concentration and conformation were stable at the focus of the optics.

\subsection{Flow velocity profile}

In order to convert the focus position into the corresponding time, the flow velocity in the channels was measured by FCS. ${ }^{32,33}$ Advantage of this approach is the large measurable velocity range, from $0.1 \mathrm{~mm} \cdot \mathrm{s}^{-1}$ to $10 \mathrm{~m} \cdot \mathrm{s}^{-1}$, and the simultaneous mea-

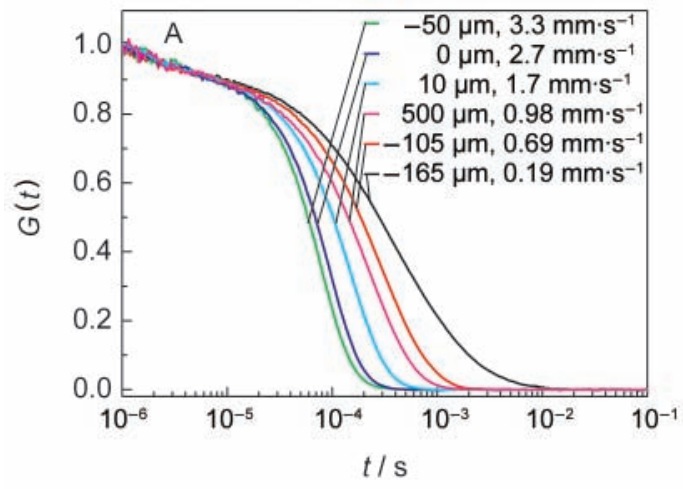

surement of the flow rate with the collection of smFRET events. FCS measured the fluorescent molecule number fluctuations in a small focal volume ${ }^{15}$ about $1 \mathrm{fL}$. In the mixing experiments, FCS curves (Fig.3A) were fit using a model of considering diffusion, flow, and singlet-triplet transition of the fluorescent molecule, , $^{27,33}$

$$
\begin{aligned}
G(\tau)= & \frac{1}{N} \cdot\left(1+\frac{\tau}{\tau_{\text {diff }}}\right)^{-1} \cdot \exp \left(-\left(\frac{\tau}{\tau_{\text {flow }}}\right)^{2} \cdot\left(1+\frac{\tau}{\tau_{\text {diff }}}\right)^{-1}\right) \cdot \\
& \left(1-K+K \cdot \exp \left(-\frac{\tau}{\tau_{\mathrm{T}}}\right)\right)
\end{aligned}
$$

where $N$ is the average number of molecules in the focus volume, $\tau_{\text {diff }}$ is the characteristic diffusion time, $\tau / \tau_{\text {flow }}$ is the characteristic flow time, $K$ is the fraction of the triplet state, and $\tau_{\mathrm{T}}$ is the characteristic triplet state time. $\tau_{\text {flow }}$ is obtained from the fitting for each FCS curve, which is related to the flow speed by

$$
v=\frac{r_{0}}{\tau_{\text {flow }}}
$$

where $r_{0}$ is the radius of the focus volume, which is determined using Rhodamine $6 \mathrm{G}^{34}$ to be $(270 \pm 7) \mathrm{nm}$.

We measured the velocities along the central axis of the channels. In an smFRET experiment each fluorescent burst needs at least dozens of effective photons ${ }^{35}$ and requires the flow rate to be about $1 \mathrm{~mm} \cdot \mathrm{s}^{-1}$ so that each molecule can spend about $1 \mathrm{~ms}$ at the focus. Fig. $3 \mathrm{~B}$ shows the velocity distri-

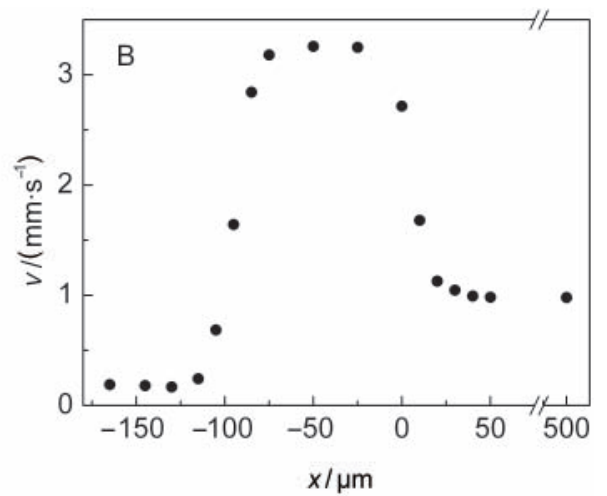

Fig.3 (A) Autocorrelation curves at different positions in the device, (B) the velocity profile in the mixer In figure A: the beginning point of the measurement channel is $0 \mu \mathrm{m}$ (Fig.1B). $-165 \mu \mathrm{m}$ is located in the centre channel with the minimum flow rate, $-50 \mu \mathrm{m}$ is in the mixing neck with the maximum flow rate to achieve rapid mixing, and $500 \mu \mathrm{m}$ is in the measurement channel with a flow rate of about 

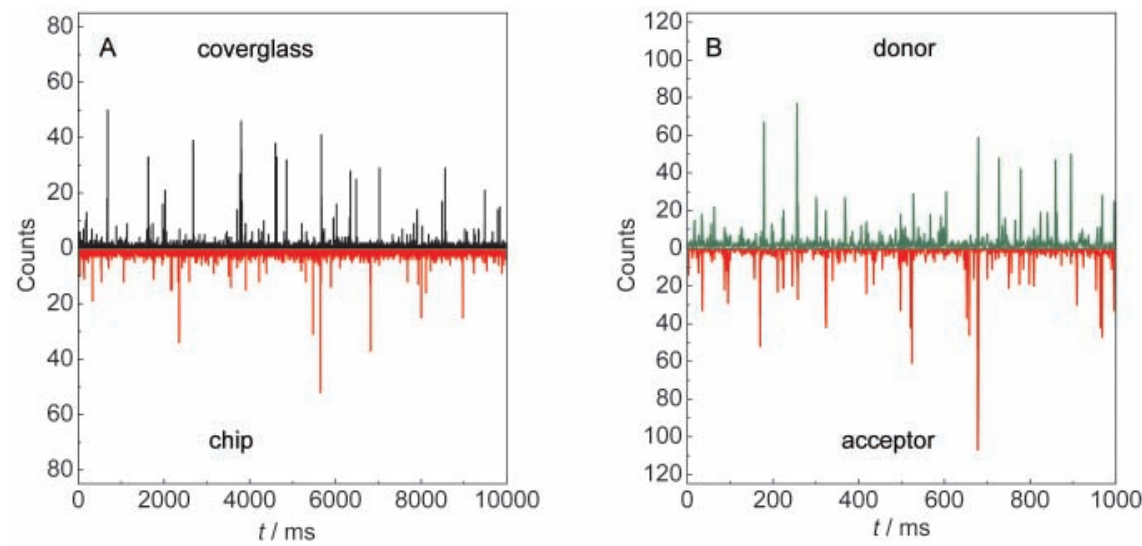

Fig.4 Single-molecule fluorescence traces

(A) single-molecule signal of a dye solution of $10 \mathrm{pmol} \cdot \mathrm{L}^{-1}$ AF546 on a coverglass and in the mixer, (B) raw smFRET data of $100 \mathrm{pmol} \cdot \mathrm{L}^{-1} \mathrm{AF} 555 \mathrm{and}$ AF647 dual labeled SNase in the mixer channel, excited by a $532 \mathrm{~nm}$ laser

bution along the central axis adjusted at such a condition.

\subsection{Single-molecule detection}

To test the fluorescence collection efficiency and the background level in the mixer channel, the single-molecule fluorescence trace of a $10 \mathrm{pmol} \cdot \mathrm{L}^{-1}$ dye solution of Alexa Fluor (AF) 546 in water was collected both on a coverglass and in the mixer channel in static experiments (Fig.4A). The dye solution was excited by a $532 \mathrm{~nm}$ laser at a power of $100 \mu \mathrm{W}$, and the collected raw data were binned into $1 \mathrm{~ms}$ dwell time. The background was fitted by a Poisson distribution, and the average photon counting rates are $0.32 \mathrm{~m} \cdot \mathrm{s}^{-1}$ on a coverglass and $0.81 \mathrm{~m} \cdot \mathrm{s}^{-1}$ in the mixer channel.

We also tested the data quality for a protein sample labeled with a dye pair in the mixer channel. A $100 \mathrm{pmol} \cdot \mathrm{L}^{-1}$ AF555 and AF647 (Invitrogen) dual labeled $\mathrm{SNase}^{30}$ mixed with 1 $\mu \mathrm{mol} \cdot \mathrm{L}^{-1}$ wild-type $\mathrm{SNase}$ to prevent labeled protein adhesion was delivered into the microfluidic device. The sample was excited with a $130 \mu \mathrm{W}$ laser beam to generate FRET events (Fig.4B). The background levels for the donor channel and acceptor channel were 1.5 and $1.2 \mathrm{~m} \cdot \mathrm{s}^{-1}$, respectively, which were higher than the pure dye solution due to impurities and higher concentration, but the signal levels were higher as well, resulting in even better signal-to-noise ratio of nearly 100 for

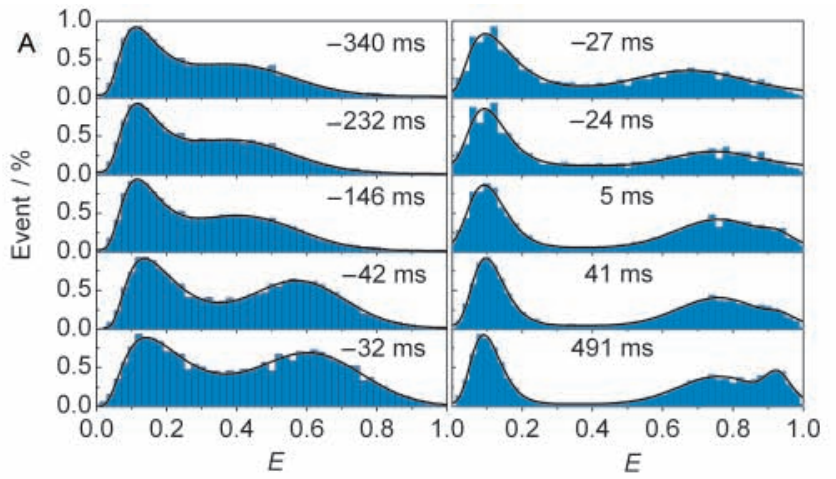

the protein sample.

\subsection{Mixing time characterized using collapse of denatured SNase}

When unfolded protein is transferred from high denaturant concentration to low concentration, the size of the protein molecule will collapse which leads to higher intramolecular smFRET efficiency and the protein collapse time is about several hundred nanoseconds, ${ }^{36}$ much faster than the mixing time. This property was used to measure the mixing time precisely. Fig.5A shows the smFRET histograms taken at different positions in the channels, fitted by lognormal and Gaussian distributions to obtain the apparent FRET efficiency of the unfolded state. The rectangular box in Fig.5B indicates the onset and completion of the mixing. The initial position was set to $E_{\text {app }}=$ $0.42,5 \%$ larger than the $E_{\text {app }}=0.40$ before mixing, and the end point was set to the first accessible position for single-molecule detection. So doing, we found that the mixing time was $150 \mathrm{~ms}$. The simplest way to enhance the mixing process is to minimize the width of mixing regions with better manufacture. Because the adequate dwell time for single-molecule detection is about $1 \mathrm{~ms}$ for fluorescent molecules flowing in the focus volume, the ultrafast mixing can be realized by a design of flow velocity deceleration. ${ }^{22}$ The mixer combining with

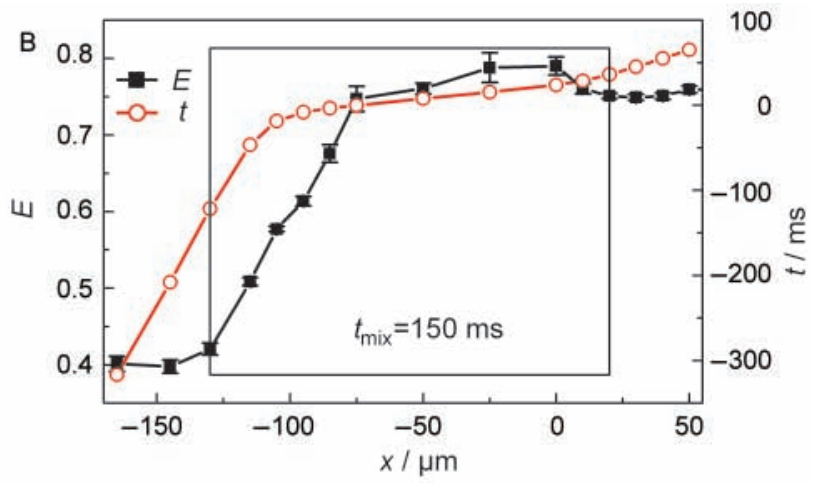

Fig.5 Mixing process elucidated by smFRET experiments

(A) smFRET histograms along the central axis of the channels, (B) the fitted FRET efficiencies of the denatured SNase; The rectangular box indicates the mixing region with a mixing time $t_{\text {mix }}$ of $150 \mathrm{~ms}$. 
smFRET for kinetics study has been applied to the measurement of the folding rate of denatured SNase. We will report our results in a future publication.

\section{Conclusions}

A microfluidic mixing system was constructed especially for single-molecule kinetic measurement, which has the advantages of high signal-to-noise ratio, stable flow rate over hours, accurate time determination by employing FCS, and easy fabrication. This technique has the capacity to study a wide variety of biological reactions requiring the combination of fast mixing, single-molecule detection, and small sample consumption. The construction of the mixer makes it possible for us to study the kinetics of various biochemical processes at a single-molecule level.

\section{References}

(1) Wolynes, P. G.; Onuchic, J. N.; Thirumalai, D. Science 1995, $267,1619$.

(2) Oliveberg, M.; Wolynes, P. G. Q. Rev. Biophys. 2005, 38, 245.

(3) Ferreon, A. C. M.; Deniz, A. A. BBA-Proteins Proteomics 2011, in press.

(4) Haas, E. ChemPhysChem 2005, 6, 858

(5) Bilsel, O.; Matthews, C. R. Curr. Opin. Struct. Biol. 2006, 16, 86.

(6) Ha, T.; Enderle, T.; Ogletree, D. F.; Chemla, D. S.; Selvin, P. R.; Weiss, S. Proc. Natl. Acad. Sci. U. S. A. 1996, 93, 6264.

(7) Weiss, S. Science 1999, 283, 1676.

(8) Deniz, A. A.; Mukhopadhyay, S.; Lemke, E. A. J. R. Soc. Interface 2008, 5,15 .

(9) Deniz, A. A.; Laurence, T. A.; Beligere, G. S.; Dahan, M.; Martin, A. B.; Chemla, D. S.; Dawson, P. E.; Schultz, P. G.; Weiss, S. Proc. Natl. Acad. Sci. U. S. A. 2000, 97, 5179.

(10) Schuler, B.; Lipman, E. A.; Eaton, W. A. Nature 2002, 419, 743.

(11) Hoffmann, A.; Kane, A.; Nettels, D.; Hertzog, D. E.; Baumgartel, P.; Lengefeld, J.; Reichardt, G.; Horsley, D. A.; Seckler, R.; Bakajin, O.; Schuler, B. Proc. Natl. Acad. Sci. U. S. A. 2007, 104, 105.

(12) Muller-Spath, S.; Soranno, A.; Hirschfeld, V.; Hofmann, H.; Ruegger, S.; Reymond, L.; Nettels, D.; Schuler, B. Proc. Natl. Acad. Sci. U. S. A. 2010, 107, 14609.

(13) Hertzog, D. E.; Michalet, X.; Jager, M.; Kong, X. X.; Santiago, J. G.; Weiss, S.; Bakajin, O. Anal. Chem. 2004, 76, 7169.

(14) Hertzog, D. E.; Ivorra, B.; Mohammadi, B.; Bakajin, O.;
Santiago, J. G. Anal. Chem. 2006, 78, 4299.

(15) Park, H. Y.; Qiu, X. Y.; Rhoades, E.; Korlach, J.; Kwok, L. W.; Zipfel, W. R.; Webb, W. W.; Pollack, L. Anal. Chem. 2006, 78, 4465.

(16) Lapidus, L. J.; Yao, S. H.; McGarrity, K. S.; Hertzog, D. E.; Tubman, E.; Bakajin, O. Biophys. J. 2007, 93, 218.

(17) Park, H. Y.; Kim, S. A.; Korlach, J.; Rhoades, E.; Kwok, L. W.; Zipfell, W. R.; Waxham, M. N.; Webb, W. W.; Pollack, L. Proc. Natl. Acad. Sci. U. S. A. 2008, 105, 542.

(18) Guo, S.; Xue, M. Q.; Qian, M. X.; Cao, T. B.; Zhao, X. S. Acta Phys. -Chim. Sin. 2007, 23, 1827. [郭 素, 薛面起, 钱民协, 曹廷丙, 赵新生. 物理化学学报, 2007, 23, 1827.]

(19) Knight, J. B.; Vishwanath, A.; Brody, J. P.; Austin, R. H. Phys. Rev. Lett. 1998, 80, 3863.

(20) Hamadani, K. M.; Weiss, S. Biophys. J. 2008, 95, 352.

(21) Pfeil, S. H.; Wickersham, C. E.; Hoffmann, A.; Lipman, E. A. Rev. Sci. Instrum. 2009, 80, 055105.

(22) Gambin, Y.; VanDelinder, V.; Ferreon, A. C. M.; Lemke, E. A.; Groisman, A.; Deniz, A. A. Nat. Methods 2011, 8, 239.

(23) Maki, K.; Cheng, H.; Dolgikh, D. A.; Roder, H. J. Mol. Biol. 2007, 368, 244

(24) Lipman, E. A.; Schuler, B.; Bakajin, O.; Eaton, W. A. Science 2003, 301, 1233.

(25) Ye, K. Q.; Wang, J. F. J. Mol. Biol. 2001, 307, 309.

(26) Kim, S. J.; Blainey, P. C.; Schroeder, C. M.; Xie, X. S. Nat. Methods 2007, 4, 397.

(27) Krichevsky, O.; Bonnet, G. Rep. Prog. Phys. 2002, 65, 251.

(28) Chen, X. D.; Zhou, Y.; Qu, P.; Zhao, X. S. J. Am. Chem. Soc. 2008, 130, 16947.

(29) Sherman, E.; Haran, G. Proc. Natl. Acad. Sci. U. S. A. 2006 , 103,11539 .

(30) Liu, P. C.; Meng, X. L.; Qu, P.; Zhao, X. S.; Wang, C. C. J. Phys. Chem. B 2009, 113, 12030.

(31) White, F. Viscous Fluid Flow, 2nd ed.; McGraw Hill: Boston, Massachusetts, 1991.

(32) Gosch, M.; Blom, H.; Holm, J.; Heino, T.; Rigler, R. Anal. Chem. 2000, 72, 3260.

(33) Kuricheti, K. K.; Buschmann, V.; Weston, K. D. Appl. Spectrosc. 2004, 58, 1180.

(34) Nie, S. M.; Chiu, D. T.; Zare, R. N. Anal. Chem. 1995, 67, 2849

(35) Gell, C.; Brockwell, D.; Smith, A. Handbook of Single Molecule Fluorescence Spectroscopy; Oxford University: Oxford, 2006.

(36) Nettels, D.; Gopich, I. V.; Hoffmann, A.; Schuler, B. Proc. Natl. Acad. Sci. U. S. A. 2007, 104, 2655 